\title{
Copepod Production in Warm, Oil Polluted Environment: A Laboratory Investigation of Temora stylifera (Dana, 1849) Adapted to the Gulf of Guinea
}

\section{Delove Asiedu}

University of Cape Coast

Emmanuel Acheampong ( $\nabla$ emmanuel.acheampong@ucc.edu.gh )

University of Cape Coast https://orcid.org/0000-0001-6243-294X

Noble Asare

University of Cape Coast

\section{Research Article}

Keywords: Feacal pellet production rate (FP), DANIDA, HOTSPOT project, GCRF, UKRI

Posted Date: April 20th, 2021

DOl: https://doi.org/10.21203/rs.3.rs-430176/v1

License: (c) (i) This work is licensed under a Creative Commons Attribution 4.0 International License.

Read Full License 


\section{Abstract}

Recent studies suggests that sea surface warming, evidently caused by greenhouse gas emissions, magnifies the toxicity of petroleum hydrocarbons on marine copepods. We assessed this understanding using Temora stylifera, a calanoid copepod common in the Atlantic Ocean and its surrounding waters, as a case study. The copepod was exposed to moderate $(0.2 \mu \mathrm{g} . \mathrm{l}-1)$ and high levels $(2.0 \mu \mathrm{g} . \mathrm{I}-1)$ of pyrene under three warming scenarios: (i) a no warming control at $28^{\circ} \mathrm{C}$, the surface temperature of the Gulf of Guinea during stable hydrographic period, (ii) moderate warming $\left(+2{ }^{\circ} \mathrm{C}\right)$ and (iii) severe warming $\left(+4{ }^{\circ} \mathrm{C}\right)$ above the control. Food ingestion rate of the copepod increased with warming without significant effect from the pollutant. Feacal pellet production rate (FP) increased by about $86 \%$ when the animal was exposed to moderate warming and pyrene at the same time, signifying reduced assimilation of food ingested in these conditions. Lowest FP (3.5 \pm 1.1 copepod-1.day-1) indicating increased food assimilation occurred when the stressors were presented either alone or together. Egg production rate and efficiency of the copepod were impacted by only warming, decreasing by $\approx 60 \%$ under both warming scenarios, consistent with previous observations. Mortality rate increased by $\approx 40 \%$ when pyrene pollution was elevated from nought to the highest level. It did not change significantly with temperature, suggesting warming did not exacerbate the lethal effect of pyrene to T. stylifera. These results are contrary to observations on other copepods and highlight the unique responses of Temora to sea surface warming and petroleum pollution.

\section{Full Text}

Due to technical limitations, full-text HTML conversion of this manuscript could not be completed. However, the manuscript can be downloaded and accessed as a PDF.

\section{Figures}




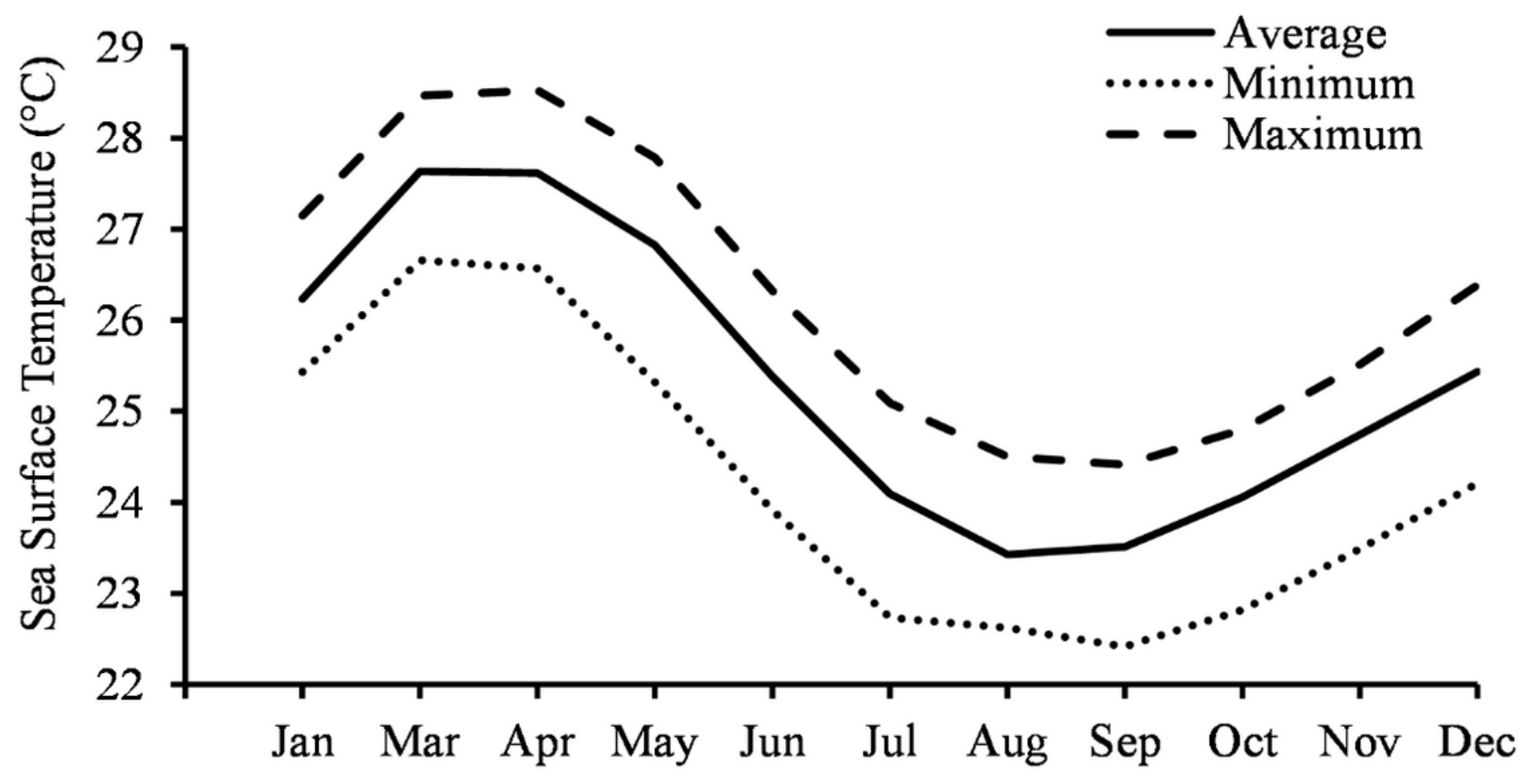

Figure 1

Surface sea temperatures observed on continental shelf of Ghana from 1948 - 2015 (data source: Ghana Meteorological Agency 2016). 

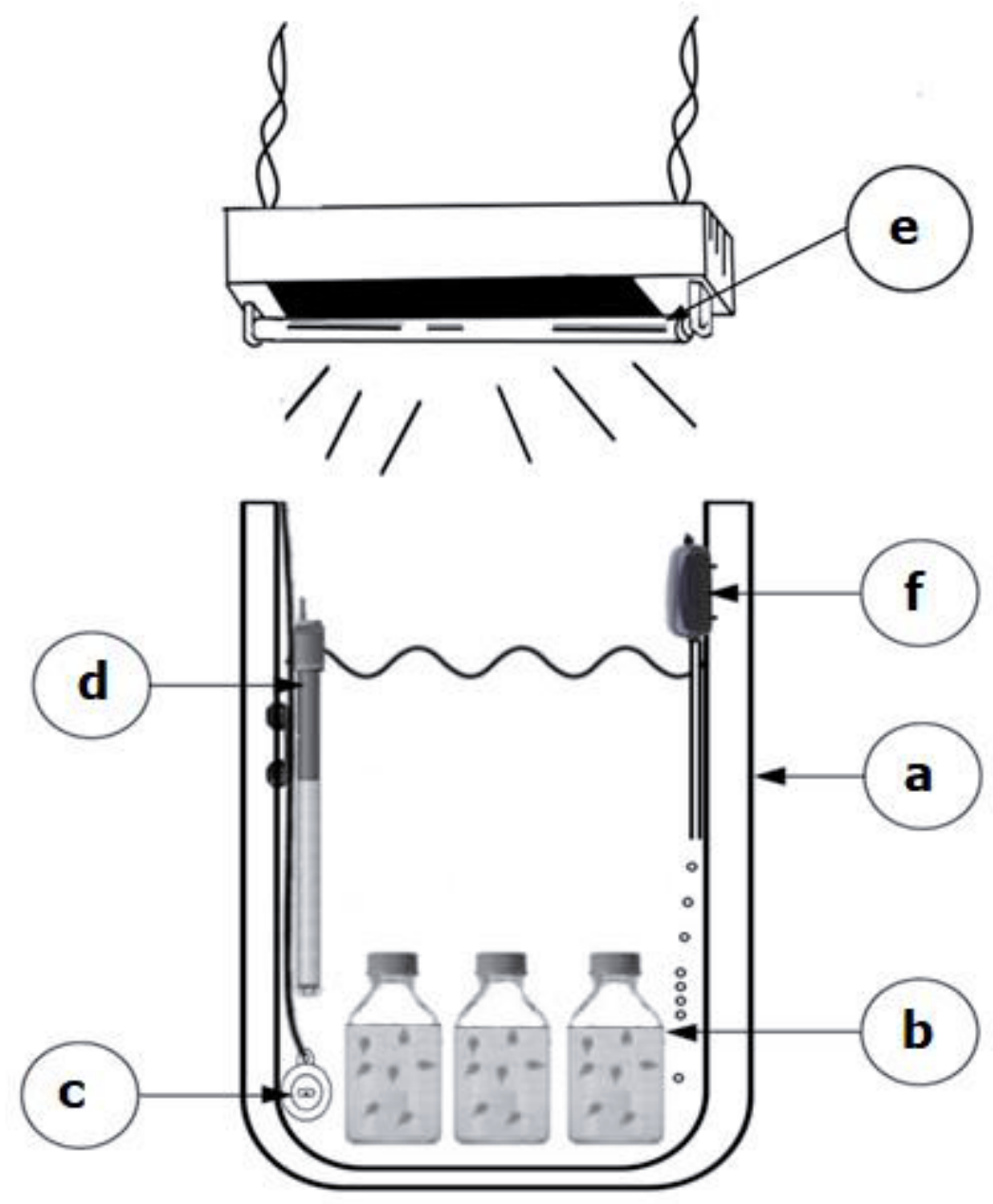

Figure 2

Schematic of experimental water bath (a) with Duran bottles filled with plankton (b), logger (c) to monitor the temperature of the bath, thermostatic heater (d) to ensure the temperature of the culture, air pump (f) for aeration to evenly distribute temperature in the bath. Illumination (e) was provided on a $12 \mathrm{~h}$ light to $12 \mathrm{~h}$ dark cycle. 

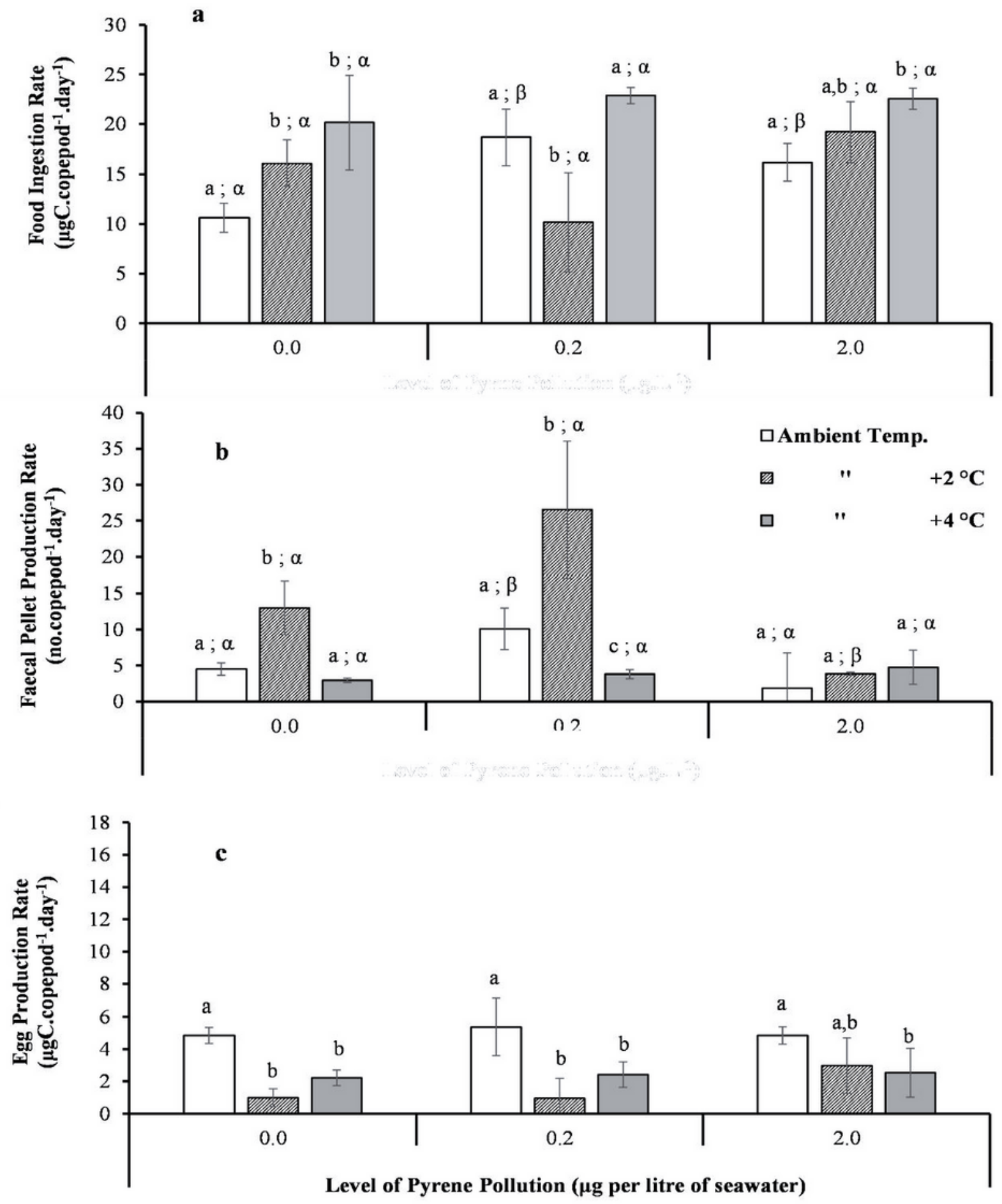

\section{Figure 3}

Temora stylifera. Changes (mean $\pm S D, N=3$ ) in (A) food ingestion, (B) faecal pellet production and (C) egg production rate of copepods exposed to different levels of pyrene and warming conditions. Mean values that are significantly different from one another are indicated by different alphabets on top of the relevant column (Tukey HSD post-hoc test at $p<0.05$ after one-way ANOVA); English and Greek alphabets 
represent comparison of observations within and between different levels of pollution treatment, respectively.
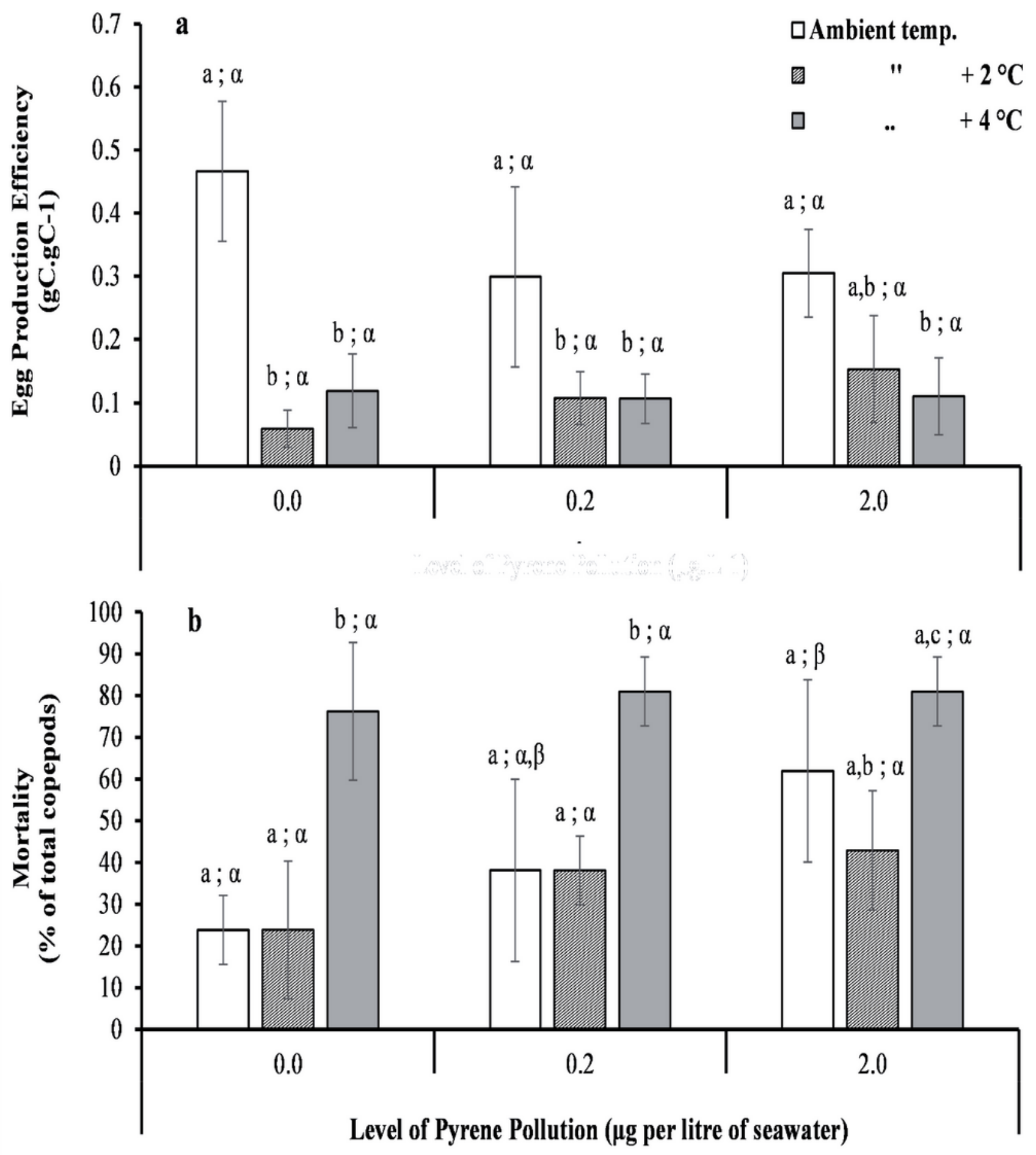

Figure 4

Temora stylifera. Changes (mean $\pm S D, N=3$ ) in (A) egg production efficiency and (B) mortality of copepods exposed to different levels of pyrene and warming for 24 hours. Mean values that are significantly different from one another are indicated by different alphabets on top of the relevant column 
(Tukey HSD post-hoc test at $p<0.05$ after one-way ANOVA); English and Greek alphabets represent comparison of observations within and between different levels of pollution treatment, respectively. 